\title{
Effect of microalloying on aging of a Cu-bearing HSLA-100 (GPT) steel
}

\author{
SANJAY PANWAR ${ }^{\dagger \dagger}$, D B GOEL*, O P PANDEY ${ }^{\dagger \dagger}$ and K SATYA PRASAD ${ }^{\dagger}$ \\ Department of Metallurgical \& Materials Engineering, Indian Institute of Technology Roorkee, \\ Roorkee 246 667, India \\ ${ }^{\dagger}$ Defence Metallurgical Research Laboratory, Hyderabad 500 058, India \\ ${ }^{\dagger}$ School of Physics \& Materials Science, Thapar Institute of Engineering \& Technology, Patiala 147 004, India
}

MS received 16 February 2006

\begin{abstract}
Investigations were carried out on aging of a HSLA-100 steel containing Cu as the major alloying element and $\mathrm{Nb}$, Ti and $\mathrm{V}$ as microalloying elements. The aging process after varying amounts of cold deformation was followed by hardness measurements and microstructural changes were studied using light and electron microscopy. Presence of $\mathrm{Ti}$ activates the formation of $(\mathrm{Nb}, \mathrm{Ti}) \mathrm{C}$ precipitates and completely suppresses the precipitation of $\mathrm{Cu}$. Even a solution treatment at $1100^{\circ} \mathrm{C}$ is not sufficient to completely dissolve $\mathrm{Nb}$ and $\mathrm{Ti}$ in the matrix and undissolved $(\mathrm{Nb}, \mathrm{Ti}) \mathrm{C}$ precipitates were observed in oil quenched state. Strain induced aging at $400^{\circ} \mathrm{C}$ causes simultaneous coarsening of existing precipitates and nucleation of fresh carbides, which results in multi-stage hardening in this steel. Strong precipitate-dislocation interactions cause retardation in recrystallization of deformation structure leading to retention of high hardness levels even on prolonged aging.
\end{abstract}

Keywords. HSLA steel; microalloying; strain-induced aging; Cu-bearing steel.

\section{Introduction}

In recent years substantial emphasis has been laid on the development of various grades of HSLA steels for making many critical components of naval and engineering applications that are subjected to complex dynamic loading. Several attempts have been made to improve the yield strength and toughness of this structural material by the addition of alloying elements, special heat treatments as well as by thermomechanical treatments along with suitable modifications in production methods. Since $\mathrm{Cu}$ is added to HSLA steels to cause precipitation strengthening, $\mathrm{Cu}$ bearing HSLA steels have attracted attention of researchers in the recent past (Dhua et al 2001a, b, 2003; Gomez et al 2002; Ghosh et al 2003, 2004, 2005; Panwar et al 2003, 2005; Bhagat et al 2004; Mao et al 2004). The design philosophy underlying such steels is to reduce the $\mathrm{C}$ content to $\sim 0.05 \mathrm{wt}$ pct, to improve weldability and to increase toughness via the precipitation hardening effects associated with high (1-2 pct) $\mathrm{Cu}$ contents.

In general, the precipitation strengthening effect of $\mathrm{Cu}$ is complimentary to the strengthening induced by other elements, which are used for precipitation hardening, such as Ti and V; these being added to steels to control austenitic grain size as well as subsequently to strengthen the trans-

*Author for correspondence (dbgmtfmt@iitr.ernet.in) formed structure of ferrite, bainite or martensite. The microalloying of these elements in $\mathrm{Cu}$-bearing HSLA steels may be of significant interest in the development of these steels. In addition to their role in grain refinement, the presence of $\mathrm{Nb}, \mathrm{Ti}$, and $\mathrm{V}$ may influence the age hardening characteristics. These elements are strong carbide formers and thus may cause formation of complex carbides at various stages of aging process. Both the temperature and time of aging are important parameters for nucleation, growth and even redissolution of the various carbides (Dutta et al 2001; Hong et al 2002, 2003a, b). Presence of these carbide forming elements is expected to affect not only the residual $\mathrm{C}$ in the matrix, but also the precipitation behaviour of $\mathrm{Cu}$ may be significantly altered. The present investigation deals with a systematic study of the effect of these elements in a Cu-bearing HSLA-100 (GPT) steel containing carbide forming microalloying elements. Since precipitate-dislocation interactions play vital role affecting various mechanical properties in HSLA steels, the effect of cold work on aging of this steel has also been studied.

\section{Experimental}

The steel with a composition (wt pct) C $0 \cdot 05, \mathrm{Mn} 1 \cdot 00, \mathrm{P}$ $0 \cdot 009$, S 0.001, Si 0.61, Cu 1.23, Ni 1.77, Cr 0.61, Mo 0.51, V 0.004, Nb 0.037, Ti 0.003, Al 0.025, Sb 0.003 and 
As 0.005 was received from Naval Research Laboratory (NRL), Washington D.C., USA, in the form of plates of dimension $300 \times 200 \times 50 \mathrm{~mm}$. This steel was termed as GPT steel by NRL. The steel in the as-received (AR) condition consisted of a mixture of ferrite and coarse carbide particles. The steel in the AR condition was given the following treatments: (a) OQ: As-received material austenitized at $1100^{\circ} \mathrm{C}$ for $180 \mathrm{~min}$, followed by oil quenching, (b) OQA : OQ treated material aged at $400^{\circ} \mathrm{C}$ for various times ranging from $5 \mathrm{~min}$ to $6000 \mathrm{~min}$, followed by water quenching, (c) C25A : OQ treated material cold worked to 25 pct reduction by rolling, followed by aging at $400^{\circ} \mathrm{C}$ for various times from $5 \mathrm{~min}$ to $6000 \mathrm{~min}$, followed by water quenching, (d) C50A: OQ treated material cold worked to 50 pct reduction by rolling, followed by aging at $400^{\circ} \mathrm{C}$ for various times from $5 \mathrm{~min}$ to $6000 \mathrm{~min}$, followed by water quenching and (e) C70A : OQ treated material cold worked to 70 pct reduction by rolling, followed by aging at $400^{\circ} \mathrm{C}$ for various times from $5 \mathrm{~min}$ to $6000 \mathrm{~min}$, followed by water quenching.

Hardness measurements were carried out on a Vickers hardness testing machine by employing a $30 \mathrm{~kg}$ load. Extensive structural investigation was conducted using high resolution microscopic techniques. For light microscopy, specimens were prepared by conventional polishing techniques. The polished specimens were etched with 2 pct nital. Reichert-Jung $\mathrm{MeF}_{3}$ optical microscope was utilized for recording microstructures. Extensive transmission electron microscopic studies were conducted on a Philips EM $430 \mathrm{~T}$ transmission electron microscope (TEM) operating at $250 \mathrm{kV}$. For this purpose thin foils of $\sim 150 \mu \mathrm{m}$ were cut from the bulk specimens using a slow speed ISOMET. Thin foils were mechanically polished to $100 \mu \mathrm{m}$. Disc specimens of $100 \mu \mathrm{m}$ thickness and $3 \mathrm{~mm}$ diameter were electropolished in a Fischione twin jet electropolisher using the electrolyte of composition (vol pct) 78 methanol, 10 lactic acid, $7 \mathrm{H}_{2} \mathrm{SO}_{4}, 3 \mathrm{HNO}_{3}$ and $2 \mathrm{HF}$ at $25 \mathrm{~V}$ and $-30^{\circ} \mathrm{C}$. Elemental analysis of precipitating phases and matrix were carried out by EDAX spectroscope attached with TEM. The facilities of TEM and EDAX were provided by the Defence Metallurgical Research Laboratory, Hyderabad.

\section{Results}

\subsection{The aging curve}

The GPT steel in the AR condition shows a hardness value of $243 \mathrm{VHN}$. Solution treatment at $1100^{\circ} \mathrm{C}$ followed by oil quenching gives a hardness value of 294 VHN. In general, cold working prior to aging increases the hardness, which increases with increasing degree of cold work. Accordingly, hardness values of $317 \mathrm{VHN}, 340 \mathrm{VHN}$ and $398 \mathrm{VHN}$ are observed after 25,50 and 70 pct cold work, respectively. Aging at $400^{\circ} \mathrm{C}$ causes multi stage hardening (PAI, PAII, PAIII) in this steel. Accordingly, multiple peaks are observed in all the treatments. Figure 1 shows the variation of hardness as a function of aging time. In general, on aging hardness first increases, attains a peak value and then decreases on further aging. Subsequent aging further enhances the hardness and the aging curves again follow the same trend. Cold working prior to aging reduces the time to reach the first hardness peaks. Accordingly, first peak (PAI) is observed after $210 \mathrm{~min}$ for C25A and after $60 \mathrm{~min}$ for $\mathrm{C} 50 \mathrm{~A}$ and $\mathrm{C} 70 \mathrm{~A}$ treatments as compared to that after $240 \mathrm{~min}$ for OQA treatment. Cold working prior to aging also increases the peak hardness value. As a result $\mathrm{C} 70 \mathrm{~A}$ treatment gives maximum hardness value of $465 \mathrm{VHN}$ after first aging peak. Figure 1 also indicates a complex aging behaviour after PAI in all the treatments. This is manifested by the different durations of second peaks (PAII) for various treatments. In the OQA treatment no second peak could be observed up to $6000 \mathrm{~min}$, whereas two hardness peaks in C25A and three peaks are observed in $\mathrm{C} 50 \mathrm{~A}$ and $\mathrm{C} 70 \mathrm{~A}$ treatments up to the aging period of $6000 \mathrm{~min}$ as seen in figure 1. In C25A treatment the PAII has been observed after $3600 \mathrm{~min}$, whereas the corresponding time for $\mathrm{C} 50 \mathrm{~A}$ and $\mathrm{C} 70 \mathrm{~A}$ treatments is reduced significantly. It is reported that in complex $\mathrm{Cu}$-bearing steels, which contain $\mathrm{Nb}$ and $\mathrm{Ti}$, both of which give precipitation hardening, multiple peaks have been observed at low aging temperatures $\left(\leq 500^{\circ} \mathrm{C}\right)$ (Cutler 1979; Krishnadev and Cutler 1979).

\subsection{Metallographic studies}

3.2a AR condition: Figure 2 shows (a) optical and (b) TEM micrographs of GPT steel in the AR condition. The optical microstructure consists of predominantly ferrite and large concentration of coarse carbide particles within the matrix. The TEM study shows a high density of dislocations together with traces of retained austenite (marked

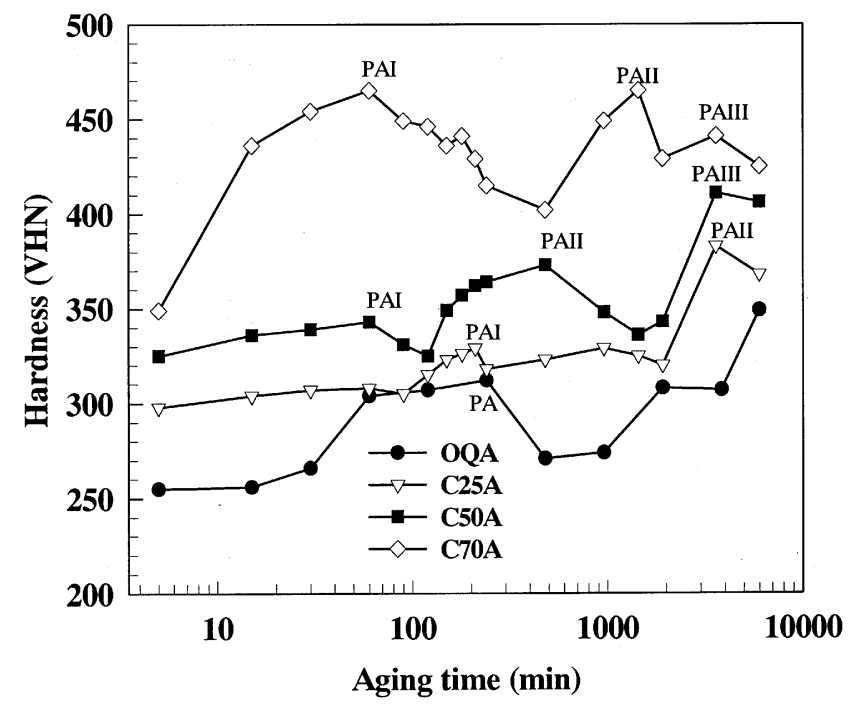

Figure 1. Variation of hardness as a function of aging time. 
by arrow in figure 2b). Existence of high density of coarse and fine carbide particles of $\mathrm{M}_{23} \mathrm{C}_{6}$ type has been observed within the matrix. The EDAX analysis reveals the presence of $\mathrm{Cr}, \mathrm{Mn}$ and $\mathrm{Cu}$ in these carbides. The EDAX analysis also reveals that in general $\mathrm{Cu}$ is always present in the precipitates, retained austenite and the matrix.

3.2b $O Q$ condition: The steel in $\mathrm{OQ}$ condition exhibits martensite plus ferrite together with a few fine carbide particles at grain boundaries as seen in the optical micro-
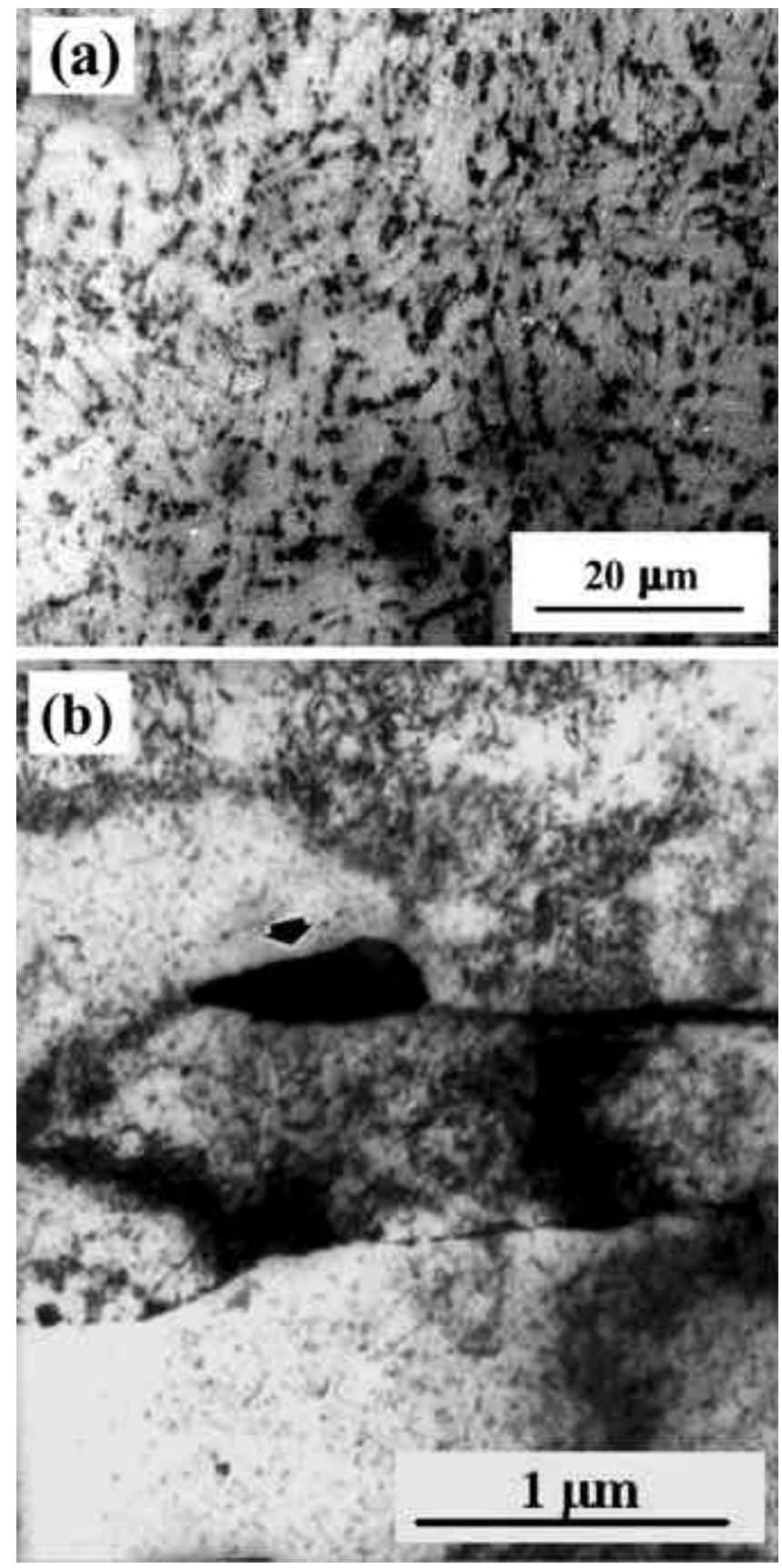

Figure 2. Microstructures in as-received condition: (a) optical microstructure and (b) TEM micrographs. The retained austenite is marked by arrow. structure in figure 3(a). The TEM micrograph (figure 3b) indicates a typical lath structure with high density of dislocations. The OQ treatment results in the precipitation of carbides predominantly at ferrite grain boundaries. These carbide particles are primarily $(\mathrm{Nb}, \mathrm{Ti}) \mathrm{C}$ as revealed by the EDAX spectrum given in figure 4. The carbides do not get completely dissolved at the austenitizing temperature of $1100^{\circ} \mathrm{C}$

3.2c OQA treatment: Aging, in general, causes the conversion of martensite into ferrite. Coarsening of existing
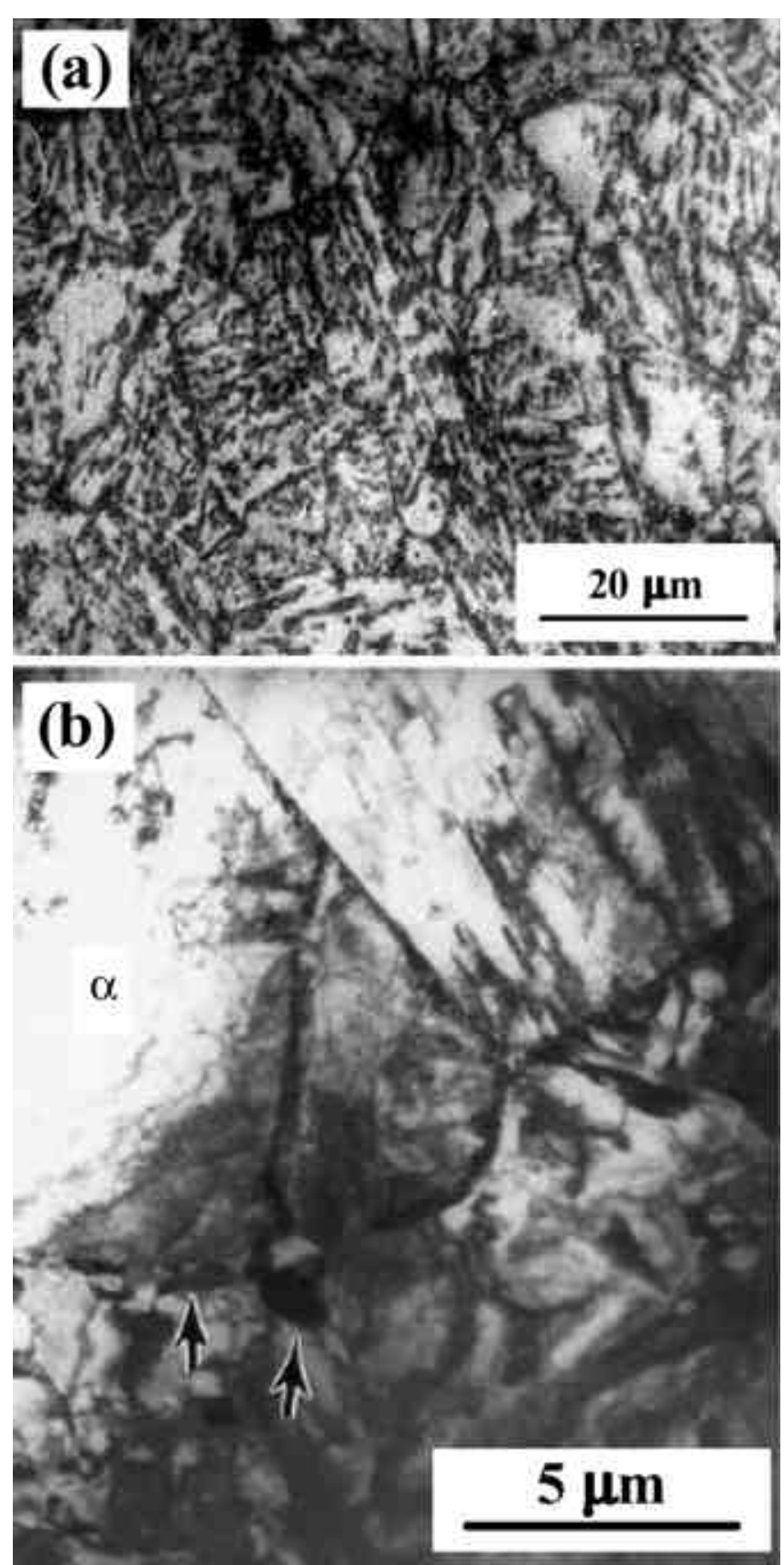

Figure 3. Microstructures in OQ condition: (a) optical microstructure and (b) TEM micrograph. The arrows show carbides at ferrite grain boundaries. 


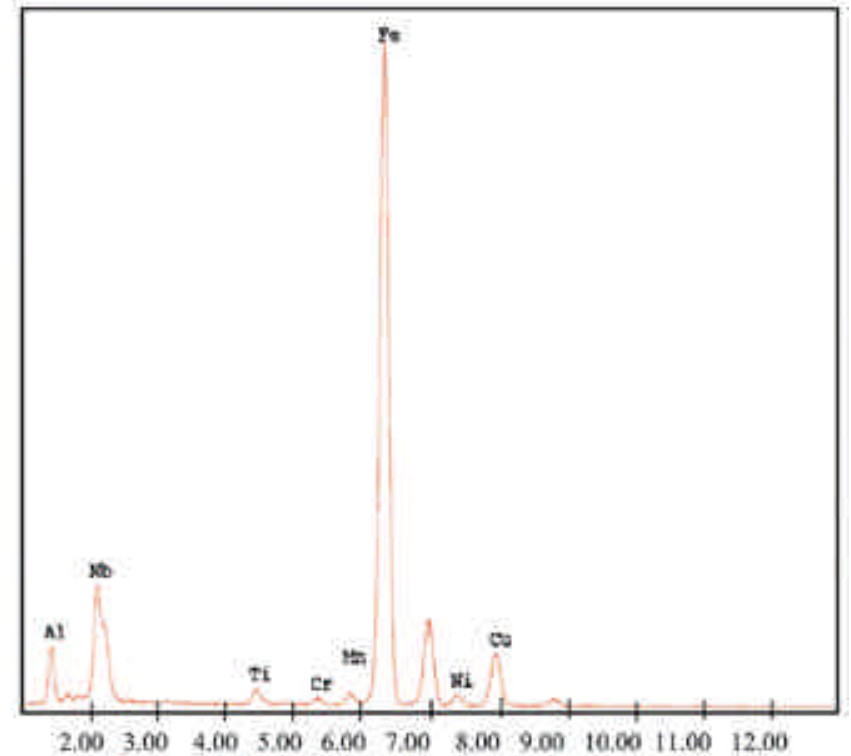

Figure 4. EDAX spectrum from $\mathrm{NbC}$ precipitates in $\mathrm{OQ}$ condition.

carbide particles occurs, which is noted by decrease in the number density and increase in average size. In addition to coarsening of existing particles, fresh nucleation of carbides also takes place on aging. Although there is softening due to conversion of martensite into ferrite and coarsening of particles, the resultant increase in hardness is due to the fresh nucleation of fine carbides at grain boundaries as well as within the grains. It is seen that continuous aging at $400^{\circ} \mathrm{C}$ causes simultaneous coarsening of existing precipitates and nucleation of fresh $(\mathrm{Nb}, \mathrm{Ti}) \mathrm{C}$ precipitates, which results in continued increase in hardness up to PAI stage observed after $240 \mathrm{~min}$ of aging. This is clearly manifested by optical microstructure in PAI condition (figure 5a), which shows coexistence of fine and coarse carbide precipitates. The network of fine precipitates is observed at grain boundaries as well as within the grains. Although large ferrite areas result in softening, the high hardness in PAI condition is due to the existence of fine precipitate network. Figure 5(b) shows microstructure after 480 min of aging, which corresponds to a significant fall in hardness after PAI condition. The structure shows coarse carbide particles in the matrix of ferrite. Subsequent aging after 480 min causes further increase in hardness due to fresh nucleation of fine carbide particles.

Figure 6 exhibits TEM micrographs in PAI condition. The TEM study shows fine particles of carbides at martensite laths, fine networks of precipitate-dislocation tangles and large carbides at ferrite grain boundaries (figure 6a). The grain boundary precipitates exhibit a complex carbide structure. At this stage the exact structure of these carbides could not be ascertained. After PAI condition there is continued coarsening of existing precipitates and formation of fresh nuclei of carbides. This process would affect the pinning effect of precipitate-dislocation tangles in a complex way. Excessive coarsening of precipitates may cause a dip in the hardness curve, as is seen after PAI. On further aging after PAI, significant coarsening of carbides weakens the dislocation-particle pinning effects, which leads to a fall in hardness. The TEM study shows that at later stages of aging the precipitates of $(\mathrm{Nb}, \mathrm{Ti}) \mathrm{C}$ continue to be nucleated, which is reflected in the transmission electron micrographs obtained after $960 \mathrm{~min}$ of aging (figure 6b). As seen in the TEM study the formation of fine $(\mathrm{Nb}, \mathrm{Ti}) \mathrm{C}$ precipitates continues to take place even after $1920 \mathrm{~min}$ (figure 6c) and $6000 \mathrm{~min}$ (figure 6d) of aging, which is the primary cause of continuous rise in hardness curve.

3.2d C25A treatment: The microstructural changes at various stages in $\mathrm{C} 25 \mathrm{~A}$ treatment are shown in figure 7. The cold worked $(\mathrm{CW})$ condition exhibits martensite plus some ferrite together with $(\mathrm{Nb}, \mathrm{Ti}) \mathrm{C}$ carbide precipitates predominantly at grain boundaries. Retained austenite is also seen at some places as marked by arrows in figure $7(\mathrm{a})$. The grain boundaries in the $\alpha$-ferrite region are quite distinctly visible presumably due to low level of deformation. Cold working causes significant increase in hardness. In general, aging causes the conversion of martensite into ferrite, recovery and recrystallization together with coarsening of existing $(\mathrm{Nb}, \mathrm{Ti}) \mathrm{C}$ precipitates. Nucleation of fresh carbide precipitates also occurs at grain boundaries as well as in the matrix as seen in optical microstructure (figure $7 b)$ recorded after 90 min of aging. The process of coarsening is seen by reduction in the number density and increase in size of the precipitates. It is also seen that the processes of coarsening of existing precipitates and nucleation of fresh carbide precipitates occur simultaneously. This explains continuous increase in hardness on aging after 25 pct deformation. The first peak (PAI) in the aging curve is seen after $210 \mathrm{~min}$. The optical microstructure in the PAI condition given in figure 7(c) reveals coarsening of existing precipitates as well as formation of fresh carbides. Continuous formation of fine carbide precipitates results in occurrence of second peak (PAII) observed after 3600 min (figure 7d).

The observations of the TEM study in C25A treatment are given in figure 8 . The TEM study in $\mathrm{CW}$ condition (figure $8 \mathrm{a}$ ) reveals existence of fine laths of martensite and regions of high dislocation density at lath boundaries as well as within the laths. Traces of retained austenite at lath boundaries are also observed as marked by arrows. Figure 8(b) shows the TEM micrograph after $60 \mathrm{~min}$ of aging. Formation of fine carbide precipitates is shown by arrows. The EDAX study reveals these carbides as ( $\mathrm{Nb}$, Ti)C. Some amount of $\mathrm{Cu}$ is also observed to be present in the Nb-rich precipitates. TEM study in the PAI condition also confirms nucleation of fine carbides (figure $8 \mathrm{c}$ ).

Polygonization of deformation structure in some regions is also observed to occur on aging. Continuous 

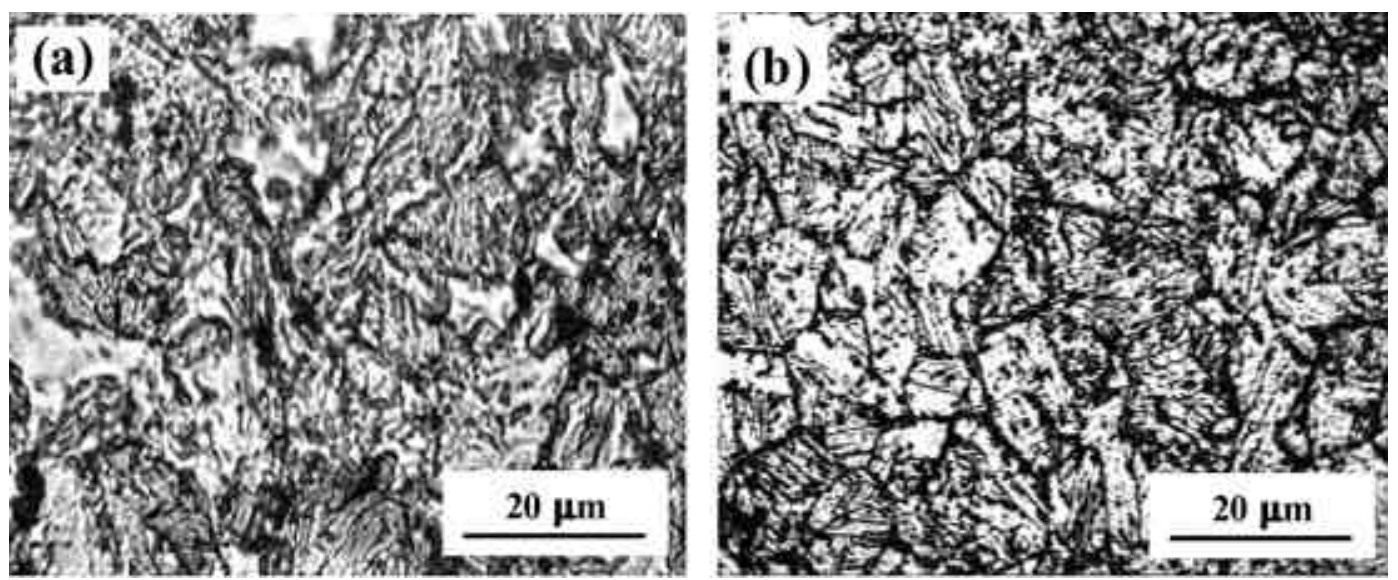

Figure 5. Optical microstructure in OQA treatment: (a) PAI condition $\left(400^{\circ} \mathrm{C}, 210 \mathrm{~min}\right)$ and (b) $480 \mathrm{~min}$.
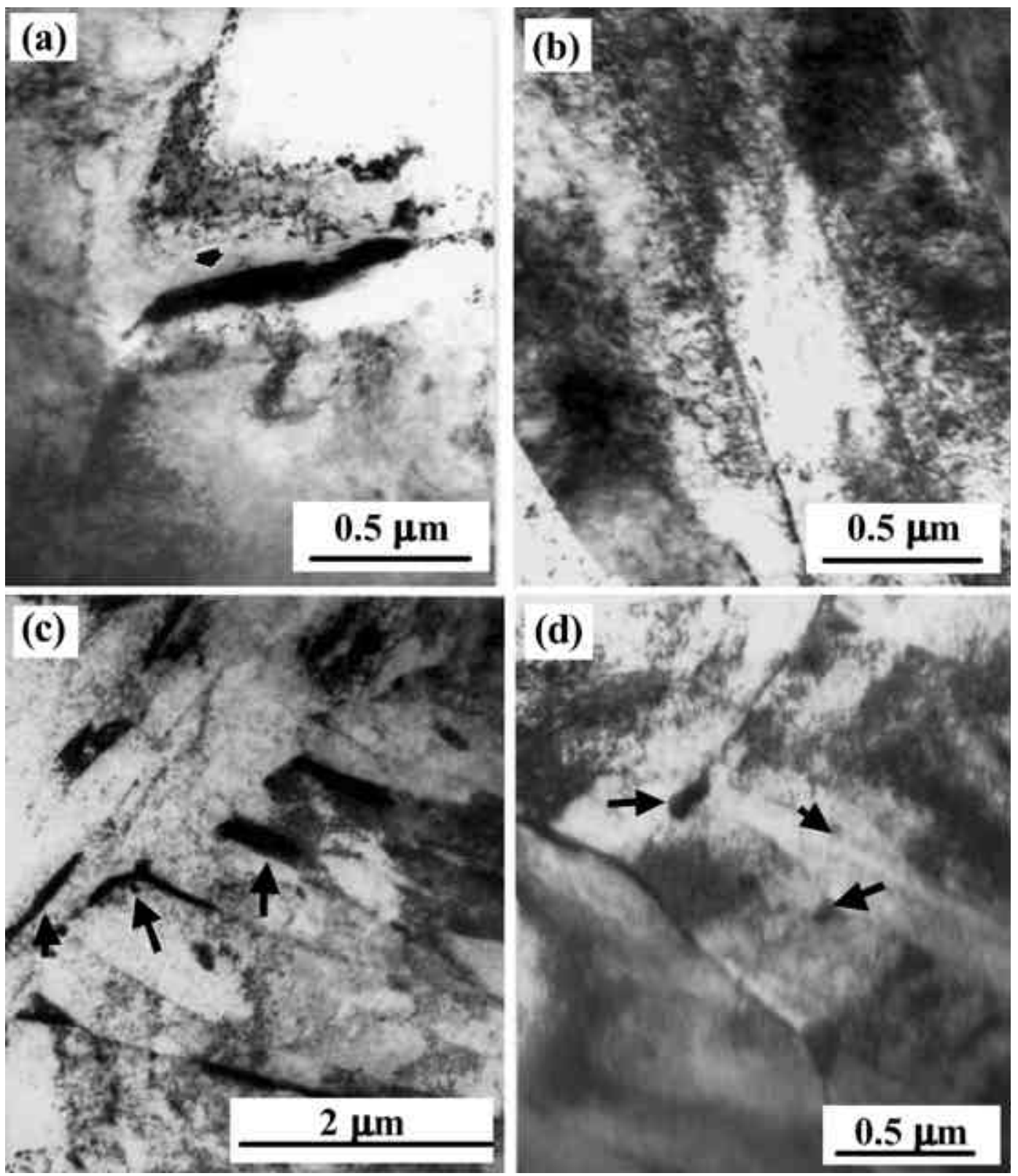

Figure 6. Transmission electron micrographs in various stages of aging in OQA treatment: (a) PAI condition $\left(400^{\circ} \mathrm{C}, 240 \mathrm{~min}\right.$ ), (b) $960 \mathrm{~min}$, (c) $1920 \mathrm{~min}$ and (d) $6000 \mathrm{~min}$. The carbides formed are marked by arrows. 

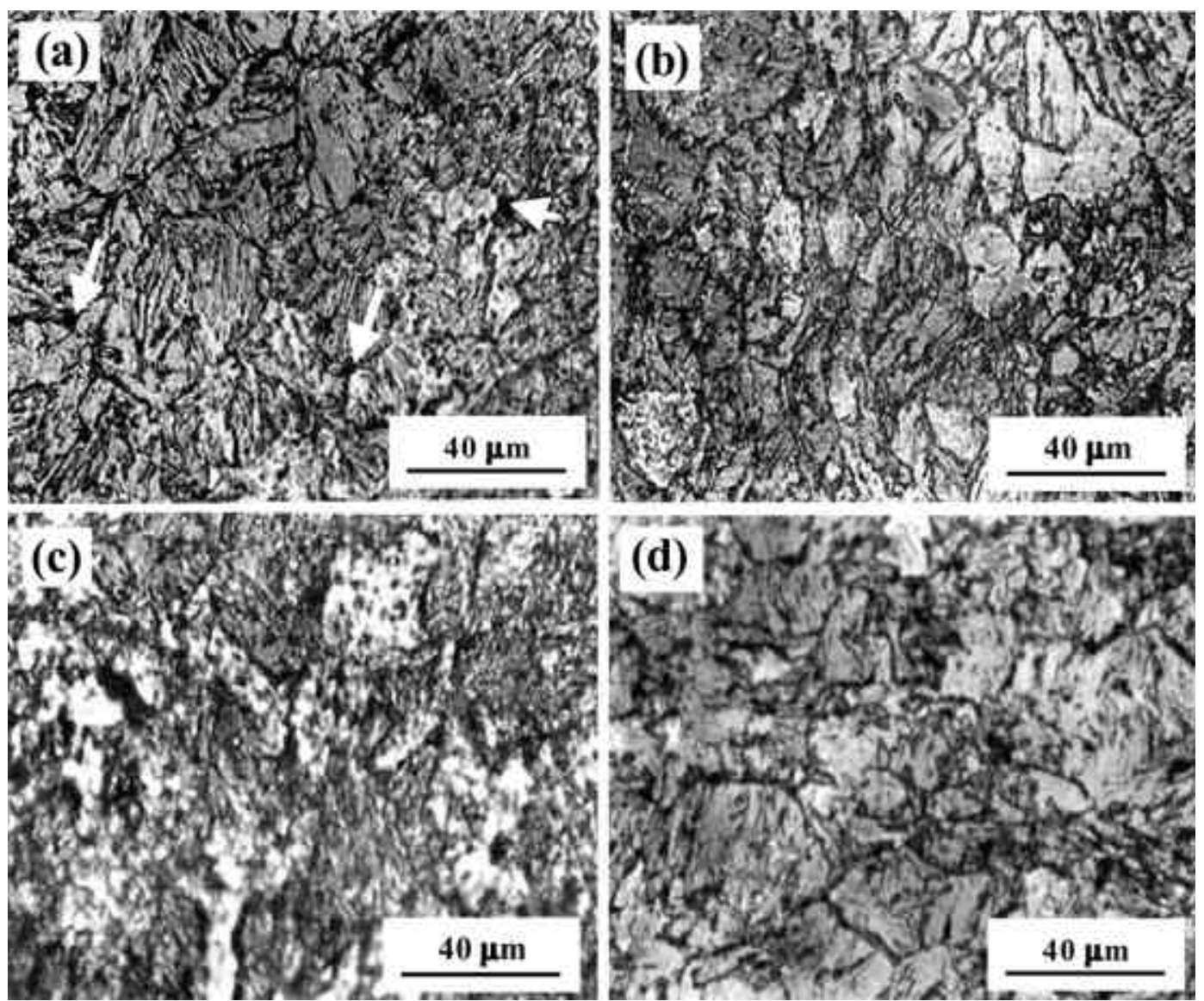

Figure 7. Optical microstructures in various stages of C25A treatment: (a) $\mathrm{CW}$ condition, (b) 90 min, (c) PAI condition $\left(400^{\circ} \mathrm{C}, 210 \mathrm{~min}\right)$ and (d) PAII condition $\left(400^{\circ} \mathrm{C}, 3600 \mathrm{~min}\right)$. The arrows in (a) indicate regions of retained austenite.

formation of fine carbide precipitates results in occurrence of PAII after $3600 \mathrm{~min}$. The fall in hardness values after PAI and PAII stages is due to temporary weakening of dislocation-precipitate pinning as confirmed by TEM study. As soon as further nucleation of fresh $(\mathrm{Nb}, \mathrm{Ti}) \mathrm{C}$ particles occurs, the hardness curve again starts rising.

3.2e C50A treatment: The microstructure after cold working to 50 pct reduction (figure 9a) exhibits fragmentation of grains, due to which the grain boundaries are not clearly visible. Aging causes conversion of martensite into ferrite, coarsening of existing carbides and nucleation of fresh carbide precipitates within the matrix. On aging, PAI is observed after $60 \mathrm{~min}$. The optical microstructure in PAI condition consists of coarsened precipitates as well as fine precipitates, as shown in figure 9(b). The optical microstructure shows no sharp grain boundaries, which signifies that till PAI stage no substantial recrystallization has occurred due to precipitate-dislocation pinning. Subsequent aging for $90 \mathrm{~min}$ results in further conversion of martensite into ferrite and coarsening of $(\mathrm{Nb}, \mathrm{Ti}) \mathrm{C}$ precipitates. With the coarsening of existing carbides, fresh nucleation of $\mathrm{Nb}$-rich precipitates in the matrix continues to occur as shown in figure 9(c) recorded after $480 \mathrm{~min}$ of aging, which corresponds to second peak of aging. Thus a mixture of coarse and fine carbide particles is always observed in the entire aging process. Subsequent aging causes another peak (PAIII) in hardness curve (figure 1) to form after $3600 \mathrm{~min}$ of aging. Large concentration of fine $(\mathrm{Nb}, \mathrm{Ti}) \mathrm{C}$ carbide particles is observed to form even after 3600 min of aging (figure 9d).

The TEM study in CW condition reveals the existence of high dislocation density and a few $(\mathrm{Nb}, \mathrm{Ti}) \mathrm{C}$ precipitates, which remained undissolved in solution treatment (figure 10a). The TEM micrographs in PAI and PAII conditions (figures $10 \mathrm{~b}, \mathrm{c}$ ) show existence of fine $(\mathrm{Nb}, \mathrm{Ti}) \mathrm{C}$ particles together with a high density of dislocations, which is responsible for the peaks in hardness curve. Partial recovery and polygonization of the matrix also occur after PAII stage as seen in figure 10(c). Further aging causes recrystallization, coarsening of existing precipitates and nucleation of fresh $(\mathrm{Nb}, \mathrm{Ti}) \mathrm{C}$ precipitates. In this treatment martensite laths appear to persist in some regions even after prolonged aging for $3600 \mathrm{~min}$ (PAIII) as seen in figure $10(\mathrm{~d})$. The TEM study also clearly shows that right from beginning of aging process, the number density 

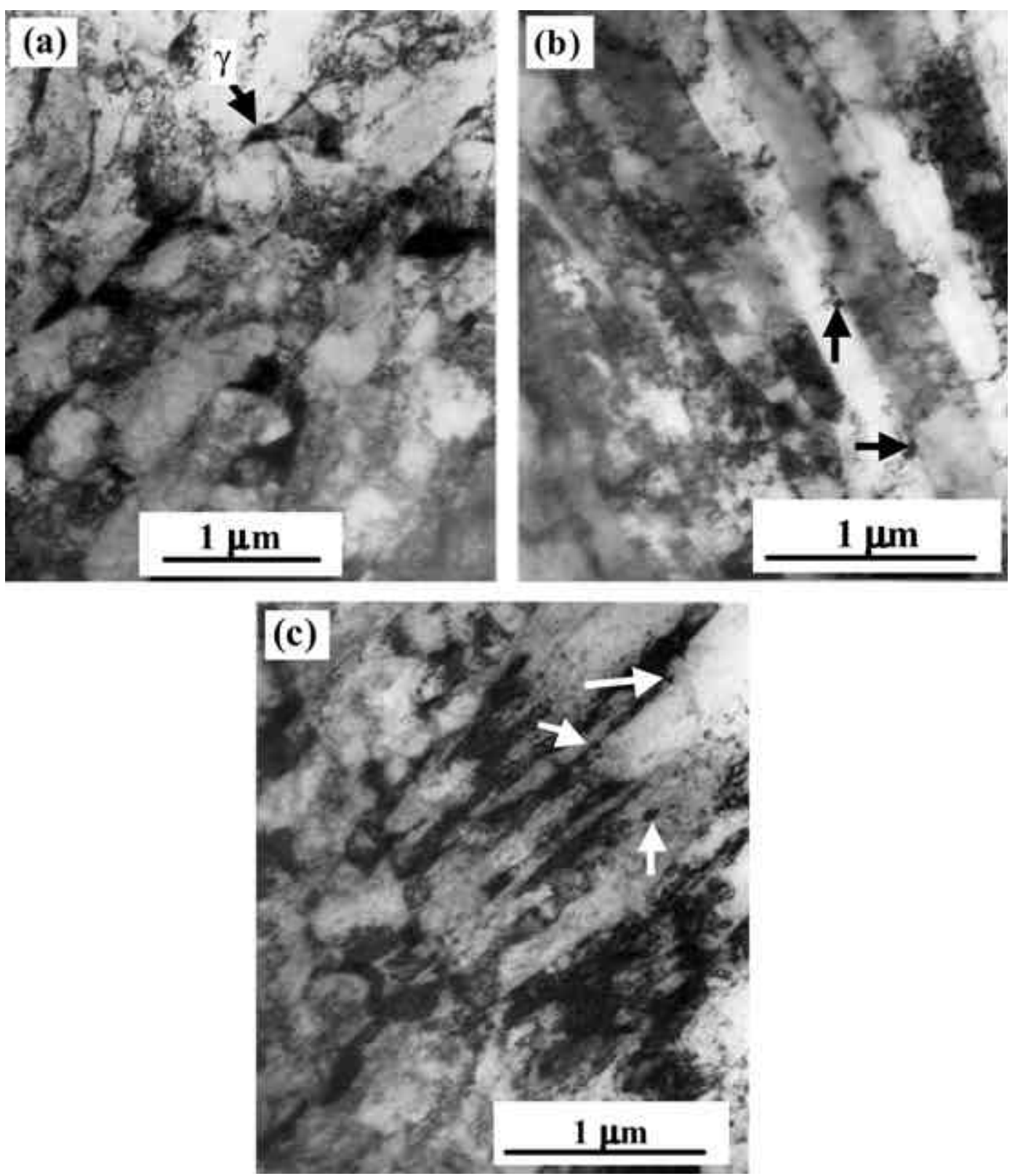

Figure 8. Transmission electron micrographs in various stages of C25A treatment: (a) $\mathrm{CW}$ condition, (b) $60 \mathrm{~min}$ and (c) PAI condition $\left(400^{\circ} \mathrm{C}, 210 \mathrm{~min}\right)$. The arrows in (a) show presence of retained austenite and in (b) \& (c) fine carbide particles.

of fresh precipitates in $\mathrm{C50 \textrm {A }}$ is higher as compared to that in $\mathrm{C} 25 \mathrm{~A}$ treatment.

3.2f C70A treatment: The metallographic observations in C70A treatment are recorded in figure 11. The general trend of precipitation and formation of hardness peaks in this treatment are almost identical to those in C50A treatment. Due to severe cold deformation, grain boundaries become fragmented and as such are not observed in optical microstructures (figure 11a). The transmission electron micrographs (figures $11 \mathrm{~b}-\mathrm{d}$ ) show martensite laths with high density of dislocations together with (Nb, Ti)C precipitates. On aging, the processes of coarsening of existing precipitates and nucleation of fine $(\mathrm{Nb}, \mathrm{Ti}) \mathrm{C}$ precipitates occur simultaneously, which leads to formation of three hardness peaks in the total aging period of $6000 \mathrm{~min}$ in this treatment (figure 1). The processes of coarsening of existing precipitates and fresh nucleation of $(\mathrm{Nb}, \mathrm{Ti}) \mathrm{C}$ carbide particles appear to be accelerated due to high deformation. The present study shows that the density of freshly nucleated $(\mathrm{Nb}, \mathrm{Ti}) \mathrm{C}$ particles increases with increasing deformation. Accordingly, C70A treatment gives highest density of finely distributed precipitates of carbides. The high level of peak hardness in C70A treatment 

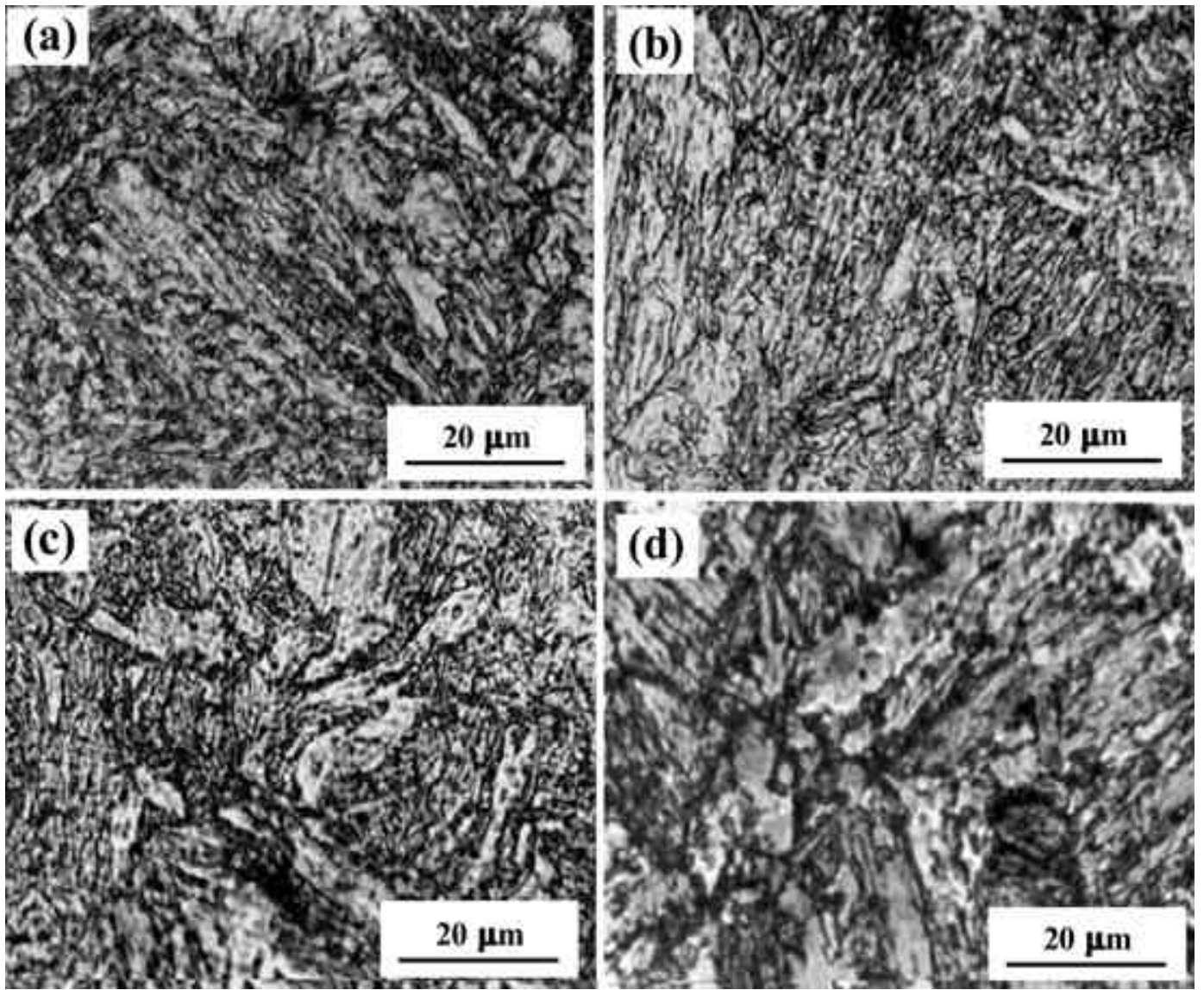

Figure 9. Optical microstructures in various stages of C50A treatment: (a) CW condition, (b) PAI condition $\left(400^{\circ} \mathrm{C}, 60 \mathrm{~min}\right),(\mathbf{c})$ PAII condition $\left(400^{\circ} \mathrm{C}, 480 \mathrm{~min}\right)$ and $(\mathbf{d})$ PAIII condition $\left(400^{\circ} \mathrm{C}, 3600 \mathrm{~min}\right)$.

is due to the high density of fine carbide precipitates together with a high density of dislocations leading to strong dislocation-particle pinning effects. Nucleation of $(\mathrm{Nb}, \mathrm{Ti}) \mathrm{C}$ carbides continues in the entire aging process. The TEM study also shows that martensite laths remain persistent in several regions even on prolonged aging as seen in figure 11.

\subsection{EDAX analysis}

The study of EDAX spectra in various stages of C25A, C50A and C70A treatments shows that the carbide precipitates forming during aging are primarily similar in chemistry to those which remain undissolved after solution treatment (figure 4). These are basically $\mathrm{Nb}$-rich and also contain Ti. In early stages of precipitation, small concentration of $\mathrm{Al}$ is also seen together with the presence of $\mathrm{Nb}$ and Ti. Copper in small concentrations is always observed to exist in the precipitating carbides. Significantly, large variations in relative concentrations of $\mathrm{Nb}$ and $\mathrm{Ti}$ are observed in precipitates existing at various stages of aging.

\section{Discussion}

The most important alloying element in GPT steel is Ti, which restricts effectively the grain growth of austenite by forming stable nitrides or carbonitrides and finally results in fine grained steel. This study shows that presence of $\mathrm{Ti}$ changes the complete precipitation behaviour of $\mathrm{Cu}$-bearing HSLA steels. In our earlier publications (Panwar et al 2003, 2005), results were reported on the effect of cold work on the precipitation behaviour of a $\mathrm{Cu}$ (1.58 pct) bearing HSLA-100 (GPP) steel, which contained $\mathrm{Nb}(0.03 \mathrm{pct})$ but no $\mathrm{V}$ and $\mathrm{Ti}$. On aging, $\mathrm{Cu}$ rich precipitates were observed in the GPP steel. The aging characteristics of GPT steel are remarkably different from those of GPP steel. Effect of cold work on aging of this steel makes the situation very complex to analyse since several processes viz. nucleation and growth of precipitates, coarsening of existing precipitates, polygonization of deformed structure and interaction of solutes and precipitates with recrystallization process occur simultaneously.

\subsection{Precipitation behaviour}

The presence of $\mathrm{Ti}$ in GPT steel makes dissolution of carbide precipitates on solution treatment at $1100^{\circ} \mathrm{C}$ difficult. It is seen that on oil quenching, undissolved carbides of $(\mathrm{Nb}, \mathrm{Ti}) \mathrm{C}$ still exist in the quenched matrix. In a recent 

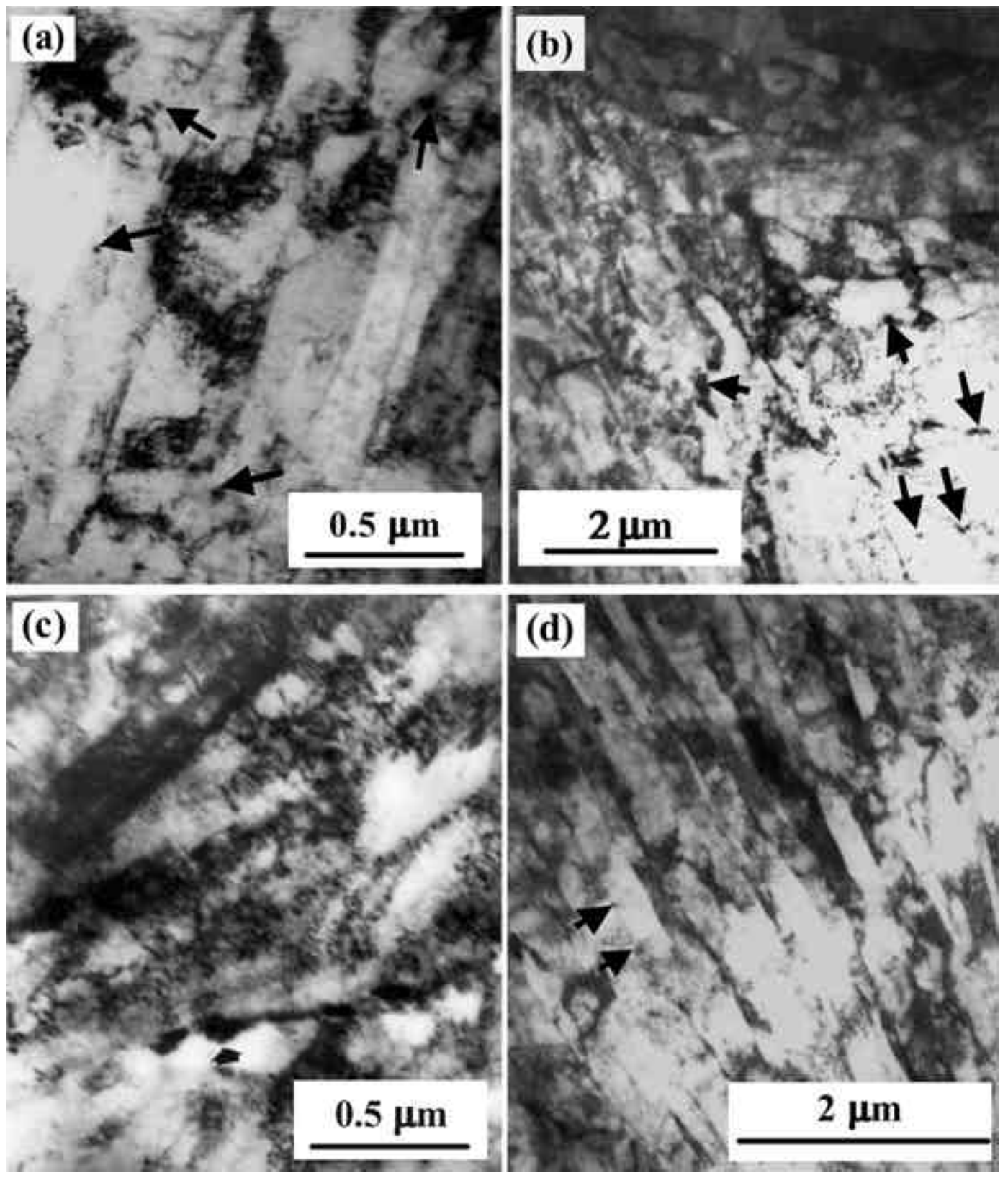

Figure 10. Transmission electron micrographs in various stages of $\mathrm{C} 50 \mathrm{~A}$ treatment: (a) $\mathrm{CW}$ condition, (b) PAI condition $\left(400^{\circ} \mathrm{C}, 60 \mathrm{~min}\right)$, (c) PAII condition $\left(400^{\circ} \mathrm{C}, 480 \mathrm{~min}\right)$ and (d) PAIII condition $\left(400^{\circ} \mathrm{C}\right.$, $3600 \mathrm{~min}$ ). Arrows show existence of carbide particles.

study on the strain-induced precipitation of $\mathrm{NbC}$ in $\mathrm{Nb}$ and $\mathrm{Nb}-\mathrm{Ti}$ microalloyed steels, Hong et al (2002) reported complete dissolution of all the precipitates in $\mathrm{Nb}$ steel at $1250^{\circ} \mathrm{C}$, whereas undissolved precipitates have been observed in $\mathrm{Nb}-\mathrm{Ti}$ steel. The undissolved precipitates are identified as Ti-rich $(\mathrm{Ti}, \mathrm{Nb})(\mathrm{C}, \mathrm{N})$ carbonitrides. In the GPT steel the EDAX spectra have shown that the undissolved precipitates contain varying amounts of $\mathrm{Nb}$ and $\mathrm{Ti}$. The concentration of $\mathrm{Nb}$ is higher than that of $\mathrm{Ti}$ in all stages of aging. This study also shows that the presence of $\mathrm{Ti}$ in this steel accelerates the precipitation of $(\mathrm{Nb}$,
Ti)C particles on aging in all treatments. This is in agreement with the study of Hong et al (2002) who observed enhancement in precipitation kinetics in HSLA steels microalloyed with both $\mathrm{Nb}$ and $\mathrm{Ti}$. The undissolved $(\mathrm{Nb}, \mathrm{Ti}) \mathrm{C}$ particles are relatively stable and act as potential sites for the nucleation of $(\mathrm{Nb}, \mathrm{Ti}) \mathrm{C}$ carbides. According to Hong et al (2002), fresh ( $\mathrm{Nb}, \mathrm{Ti}) \mathrm{C}$ carbides are precipitated coherently on the pre-existing $(\mathrm{Nb}, \mathrm{Ti})(\mathrm{C}, \mathrm{N})$ precipitates. The lattice mismatch between the pre-existing carbide particles and freshly nucleating $(\mathrm{Nb}, \mathrm{Ti}) \mathrm{C}$ particles is very small $(\sim 2 \mathrm{pct})$. The strain energy arising from 

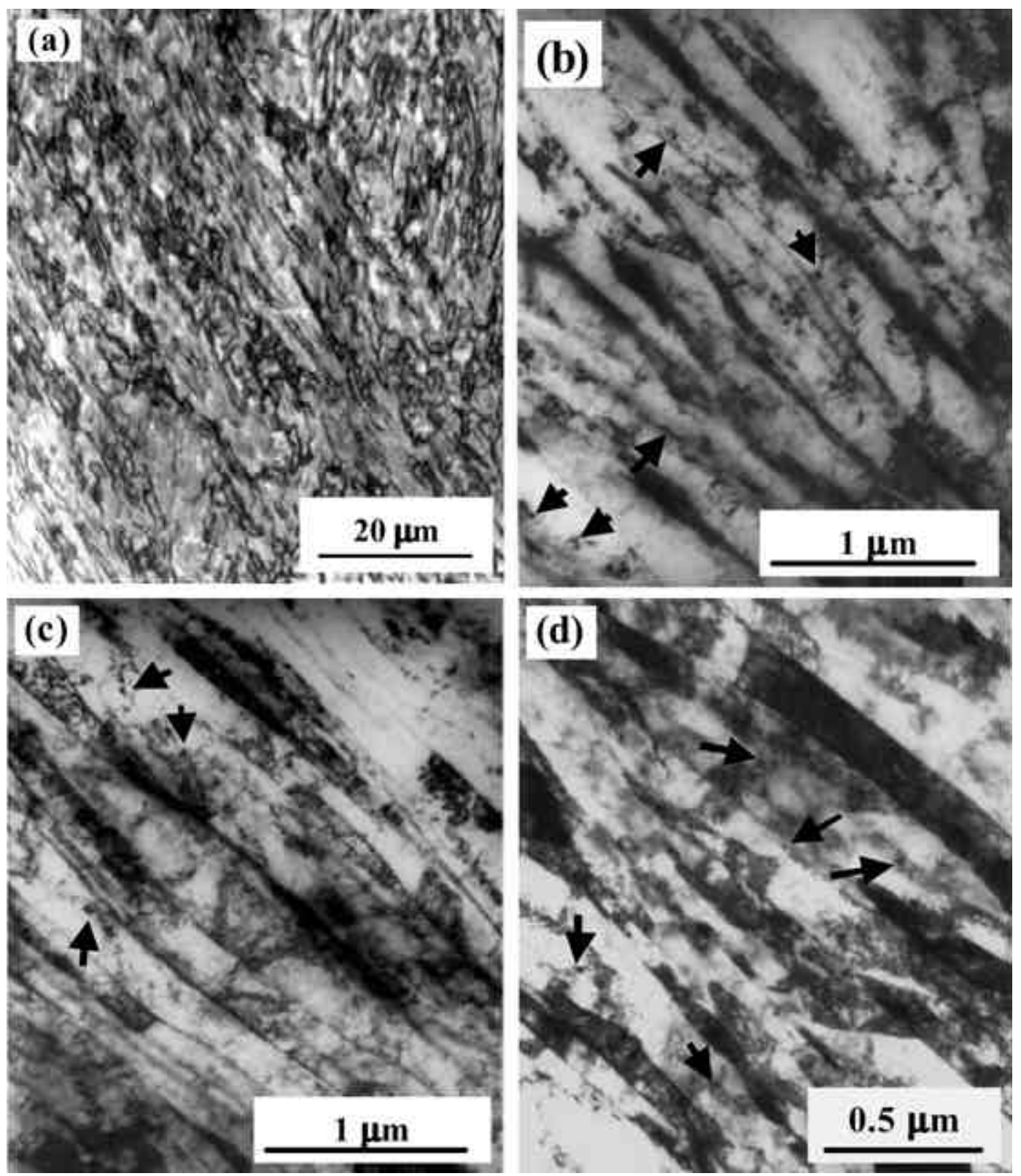

Figure 11. Metallographic structures in various stages of $\mathrm{C} 70 \mathrm{~A}$ treatment: (a) optical microstructure in $\mathrm{CW}$ condition and transmission electron micrographs in (b) $\mathrm{CW}$ condition, (c) PAI condition $\left(400^{\circ} \mathrm{C}\right.$, $60 \mathrm{~min})$ and (d) PAII condition $\left(400^{\circ} \mathrm{C}, 1440 \mathrm{~min}\right)$. Arrows show existence of fine carbide particles.

this small lattice misfit is thus negligible in comparison to the large decrease of interfacial energy between preexisting undissolved carbide particles and the nucleating $(\mathrm{Nb}, \mathrm{Ti}) \mathrm{C}$ precipitates. Thus heterogeneous nucleation of $(\mathrm{Nb}, \mathrm{Ti}) \mathrm{C}$ precipitates occurs on pre-existing carbides due to the decrease of energy barrier for nucleation.

The present study also reveals varying concentrations of $\mathrm{Nb}$ and $\mathrm{Ti}$ in carbide precipitates forming on aging. In a steel microalloyed with $\mathrm{Nb}$ and $\mathrm{Ti}$, Hong et al (2002) observed that only about 8 pct of total $\mathrm{Nb}$ content of the steel was tied up within the undissolved $(\mathrm{Ti}, \mathrm{Nb})(\mathrm{C}, \mathrm{N})$ carbonitrides, whereas after a pre-strain of 0.3 and $950^{\circ} \mathrm{C}$ followed by holding for $8 \mathrm{~s}$, about 14 pct of total $\mathrm{Nb}$ con- tent of the steel was available in $(\mathrm{Nb}, \mathrm{Ti})(\mathrm{C}, \mathrm{N})$ carbides precipitating coherently at the undissolved carbonitrides. This obviously is due to a very sensitive role of $\mathrm{Ti}$ in the precipitation kinetics in GPT steel. The presence of $\mathrm{Ti}$ significantly accelerates the precipitation process and as a significant portion of $\mathrm{Ti}$ already gets combined with the undissolved carbide particles, the relative concentration of $\mathrm{Ti}$ in precipitates forming on aging is low. Addition of $\mathrm{Ti}$ is believed to cause austenite grain refinement in HSLA steels. It may be argued that the influence of Ti on precipitation kinetics in this steel is through its effect on austenite grain refinement as reported by Dutta and Sellars (1987). In deformed steels, however, the effect of austenite 
grain size is not likely to influence the precipitation kinetics of $(\mathrm{Nb}, \mathrm{Ti}) \mathrm{C}$ carbides; since in deformed matrix nucleation of strain induced precipitates is more likely to take place mainly at dislocations and sub boundaries developed by deformation. Presence of dislocations causes development of potential nucleation sites and as such the rate of precipitation of $(\mathrm{Nb}, \mathrm{Ti}) \mathrm{C}$ carbides is expected to increase with increasing deformation. Accordingly, in this study a higher density of $(\mathrm{Nb}, \mathrm{Ti}) \mathrm{C}$ precipitates is observed in C70A treatment as compared to treatments involving lower degrees of deformation. Since the matrix contains a substantially high density of dislocations even at later stages of aging, continuous nucleation of fine $(\mathrm{Nb}, \mathrm{Ti}) \mathrm{C}$ particles is observed even up to $6000 \mathrm{~min}$ of aging in each treatment.

A major observation made in this study is that precipitation coarsening begins at very early stage of aging and leads to a significant decrease in precipitate number density. It is also seen that growth and coarsening occur simultaneously during the precipitation of fine $(\mathrm{Nb}, \mathrm{Ti}) \mathrm{C}$ precipitates. A comprehensive analysis of the precipitation kinetics involving nucleation, growth and coarsening of precipitates in this steel poses a very complex challenge. Earlier work has shown that the presence of dislocations causes a significant acceleration in nucleation, growth and coarsening of precipitates (Sellars 1990; Dutta et al 1992, 2001; Palmiere et al 1994; Liu 1995). The early occurrence of coarsening is assumed to be an essential feature in strain induced precipitation (Dutta et al 1992). Dutta et al (2001) have shown that the coarsening of precipitates leading to growth of bigger precipitates at the expense of smaller precipitates cannot occur if the diffusion is dominated by volume diffusion. In this study the continuous growth and coarsening of existing $(\mathrm{Nb}, \mathrm{Ti}) \mathrm{C}$ precipitates together with nucleation of fresh $(\mathrm{Nb}, \mathrm{Ti}) \mathrm{C}$ precipitates indicate that bulk diffusion cannot be the dominant mechanism for precipitation and coarsening. These observations can only be explained by considering the effect of accelerated solute diffusion along the dislocations, whereby coarsening can easily occur since the precipitates are interconnected through the dislocation networks. Due to increasing enhancement of precipitation kinetics as a result of prior deformation, both coarsening of existing precipitates and nucleation of fine $(\mathrm{Nb}, \mathrm{Ti}) \mathrm{C}$ precipitates will accelerate with increasing degree of cold work. Accordingly, highest density of fine precipitates always exists at every stage in C70A treatment. The general level of precipitation strengthening as observed by hardness curves (figure 1), therefore, increases with degree of cold work. The C70A treatment gives maximum hardness level, whereas in undeformed specimens (OQA treatment) the hardness level is lowest.

\subsection{Effect on copper precipitation}

A remarkable feature observed in GPT steel is that aging in any treatment does not cause formation of $\mathrm{Cu}$ rich preci- pitates. Thus complete suppression of $\mathrm{Cu}$ precipitation in GPT steel is attributed to the presence of Ti. As mentioned earlier, presence of $\mathrm{Ti}$ substantially activates the precipitation process in Nb-containing HSLA steels. The plastic deformation induced prior to aging also accelerates the precipitation of $(\mathrm{Nb}, \mathrm{Ti}) \mathrm{C}$ particles. EDAX spectral analysis of precipitates reveals that some amount of $\mathrm{Cu}$ is always present in $(\mathrm{Nb}, \mathrm{Ti}) \mathrm{C}$ precipitates. In the beginning the kinetics of precipitation of $(\mathrm{Nb}, \mathrm{Ti}) \mathrm{C}$ is substantially faster than that of $\mathrm{Cu}$, due to which $(\mathrm{Nb}, \mathrm{Ti}) \mathrm{C}$ carbides precipitate in preference to $\mathrm{Cu}$. As the aging progresses, there is continued precipitation of $(\mathrm{Nb}, \mathrm{Ti}) \mathrm{C}$ particles containing $\mathrm{Cu}$ in solution. The matrix, therefore, continuously depletes in $\mathrm{Cu}$ and the possibility of $\mathrm{Cu}$ precipitation dwindles as the aging progresses. This remarkable behaviour of $(\mathrm{Ti}+\mathrm{Nb})$ combine in suppressing the precipitation of $\mathrm{Cu}$ rich particles in this steel may seriously affect the work hardening characteristics and the resultant mechanical properties in the GPT steel.

\subsection{Mechanism of hardening}

In the GPT steel the hardening effects can be attributed to (i) presence of $\mathrm{Nb}$ in the matrix, (ii) existence of $(\mathrm{Nb}$, Ti)C-dislocation tangles and (iii) recrystallization process occurring at elevated temperatures of aging. Presence of $\mathrm{Nb}$ causes (i) grain refinement and (ii) resistance to recrystallization. Niobium is known to be the element that substantially delays static recrystallization kinetics even when it is in solution (Kajalainen et al 1995; Medina 1995; Li et al 1996; Gomez et al 2002). Medina et al (1999) have observed the recrystallization-precipitation interaction in $\mathrm{Nb}$ microalloyed steels. Gomez et al (2002) in a recent study on a low $\mathrm{Nb}$ microalloyed steel observed that inhibition of recrystallization does not always coincide with start of strain induced precipitation. Recrystallization is a nucleation and growth process and is characterized by an incubation period. Therefore, retardation in recrystallization may not be a direct consequence of formation of precipitates.

In the presence of $\mathrm{Ti}$, the strengthening effects of $\mathrm{Nb}$ in solution may be significantly diluted due to rapid $(\mathrm{Nb}$, Ti)C precipitation. The pinning effects of dislocation$(\mathrm{Nb}, \mathrm{Ti}) \mathrm{C}$ precipitates are more likely to dominate the mechanism of strengthening in this steel. With increase in deformation, an increase is observed in the dislocation density and nucleation kinetics of carbide precipitates. This leads to enhanced dislocation pinning effects and higher hardness levels. Thus C70A treatment gives highest strengthening, whereas in OQA treatment involving no prior cold work the strengthening effect is minimum. The high density of dislocations and fine $(\mathrm{Nb}, \mathrm{Ti}) \mathrm{C}$ carbides not only provide strengthening but also resistance to softening. This study shows that recrystallization as manifested by observation of grain boundaries is retarded with increase 
in degree of prior deformation. TEM study also shows that in C70A treatment the dislocation density remains substantially high even after aging up to PAII stage (figure 11d).

It is well known that recrystallization is affected by precipitate particle size and distribution. It is, therefore, expected that the dislocation pinning effect should be reduced as the precipitate particle undergoes coarsening. The dip in hardness values after various peaks (figure 1) is due to rapid coarsening of pre-existing $(\mathrm{Nb}, \mathrm{Ti}) \mathrm{C}$ precipitates and lack of fine precipitate-dislocation tangles. As aging continues, more such precipitate-dislocation tangles are generated and the hardness again rises further. Thus the interaction between the dislocation networks with nucleation, growth and coarsening of precipitates leads to formation of several hardness peaks in various treatments as seen in figure 1 .

\section{Acknowledgement}

The steel used in this investigation was received from the Naval Research Laboratory, Washington (USA) under an Indo-US collaboration program.

\section{References}

Bhagat A N, Pabi S K, Ranganathan S and Mohanty O N 2004 ISIJ Int. $\mathbf{4 4} 115$

Cutler L R 1979 in Copper in iron and steel (eds) L McDonald Schetky and I LeMay (New York: John-Wiley \& Sons) p. 26

Dhua S K, Mukerjee D and Sarma D S 2001a Metall. Mater. Trans. A32 2259

Dhua S K, Ray A and Sarma D S 2001b Mater. Sci. Eng. A318 197
Dhua S K, Mukerjee D and Sarma D S 2003 Metall. Mater. Trans. A34 241

Dutta B and Sellars C M 1987 Mater. Sci. Technol. 3197

Dutta B, Valdes E and Sellars C M 1992 Acta Mater. 40653

Dutta B, Palmiere E J and Sellars C M 2001 Acta Mater. 49785

Ghosh A, Das S, Chatterjee S, Mishra B and Ramachandra Rao P 2003 Mater. Sci. Eng. A348 299

Ghosh A, Mishra B, Das S and Chatterjee S 2004 Mater. Sci. Eng. A374 43

Ghosh A, Mishra B, Das S and Chatterjee S 2005 Mater. Sci. Eng. A396 320

Gomez M, Medina S F, Quispe A and Valles P 2002 ISIJ Int. 42423

Hong S G, Kang K B and Park C G 2002 Scr. Mater. 46163

Hong S C, Lim S H, Hong H S, Lee K J, Shin D H and Lee K S 2003a Mater. Sci. Eng. A355 241

Hong S G, Jun H J, Kang K B and Park C G 2003b Scr. Mater. 481201

Kajalainen L P, Maccagno T and Jonas J J 1995 ISIJ Int. 35 1523

Krishnadev M R and Cutler L R 1979 in Copper in iron and steel (eds) L McDonald Schetky and I LeMay (New York: John-Wiley \& Sons) p. 26

Li G, Maccagno T, Bai D Q and Jonas J J 1996 ISIJ Int. 361479

Liu W J 1995 Metall. Mater. Trans. A26 1641

Mao W, Ren H and Yu Y 2004 Z. Metallkd. 9557

Medina S F 1995 Scr. Mater. 3243

Medina S F, Quispe A, Valles P and Banos J L 1999 ISIJ Int. 39913

Palmiere E J, Garcia C I and DeArdo A J 1994 Metall. Mater. Trans. A25 277

Panwar S, Goel D B, Pandey O P and Prasad K S 2003 Bull. Mater. Sci. 26441

Panwar S, Goel D B and Pandey O P 2005 Bull. Mater. Sci. 28 259

Sellars C M 1990 Mater. Sci. Technol. 61072 